\title{
Turning Crisis into Opportunity: Nature of Science and Scientific Inquiry as Illustrated in the Scientific Research on Severe Acute Respiratory Syndrome
}

\author{
Siu Ling Wong · Jenny Kwan · Derek Hodson · Benny Hin Wai Yung
}

Published online: 9 October 2007

(C) Springer Science+Business Media B.V. 2007

\begin{abstract}
Interviews with key scientists who had conducted research on Severe Acute Respiratory Syndrome (SARS), together with analysis of media reports, documentaries and other literature published during and after the SARS epidemic, revealed many interesting aspects of the nature of science (NOS) and scientific inquiry in contemporary scientific research in the rapidly growing field of molecular biology. The story of SARS illustrates vividly some NOS features advocated in the school science curriculum, including the tentative nature of scientific knowledge, theory-laden observation and interpretation, multiplicity of approaches adopted in scientific inquiry, the inter-relationship between science and technology, and the nexus of science, politics, social and cultural practices. The story also provided some insights into a number of NOS features less emphasised in the school curriculum-for example, the need to combine and coordinate expertise in a number of scientific fields, the intense competition between research groups (suspended during the SARS crisis), the significance of affective issues relating to intellectual honesty and the courage to challenge authority, the pressure of funding issues on the conduct of research and the 'peace of mind' of researchers, These less emphasised elements provided empirical evidence that NOS knowledge, like scientific knowledge itself, changes over time. They reflected the need for teachers and curriculum planners to revisit and reconsider whether the features of NOS currently included in the school science curriculum are fully reflective of the practice of science in the 21 st century. In this paper, we also report on how we made use of extracts from the news reports and documentaries on SARS, together with episodes from the scientists' interviews, to develop a multimedia instructional package for explicitly teaching the prominent features of NOS and scientific inquiry identified in the SARS research.
\end{abstract}

Keywords Nature of science $\cdot$ Scientific inquiry $\cdot$ Scientists ·

Development of instructional materials

S. L. Wong $(\varangle) \cdot$ J. Kwan · D. Hodson · B. H. W. Yung Faculty of Education, The University of Hong Kong, Pokfulam Road, Hong Kong SAR, China e-mail: aslwong@hkucc.hku.hk 


\section{Introduction}

Understanding the nature of science (NOS), especially the key features of the scientific endeavour, has long been regarded as a major component of science literacy and an important objective of science curricula in many countries (e.g. American Association for the Advancement of Science 1993; Council of Ministers of Education 1997; Millar and Osborne 1998) ${ }^{1}$ However, it has been consistently reported that many students, and even many teachers, do not possess adequate NOS understanding (Lederman 1992; Abd-ElKhalick and Lederman 2000; Moss et al. 2001; Finson 2002). While there have been many attempts to improve teachers' understanding of NOS, Abd-El-Khalick and Lederman (2000) report that little success has been achieved. Their critical review suggests that 'approaches that utilise elements from history and philosophy of science and/or direct instruction on NOS are more effective in achieving that end than approaches that utilise science process-skills instruction or non-reflective inquiry-based activities' (p. 694). The authors also point out that while there might be compelling theoretical arguments to support the effectiveness of history of science and philosophy of science in improving learners' NOS conceptions, further empirical research is essential. Among research efforts in this direction, Irwin (2000) demonstrates encouraging results with a group of 14-yearold students by integrating substantial amounts of historical material into the topic of Atoms and the Periodic Table. Lin and Chen (2002) also provide empirical evidence of positive impact on understanding of NOS among a group of prospective chemistry teachers by integrating historical cases into a pre-service teacher education programme.

Bell et al. (2003) and Schwartz et al. (2004) have investigated the effectiveness of promoting NOS understanding among high school students and pre-service teachers by providing the authentic research experience of working with practicing scientists. Results show that better understanding of NOS and the nature of scientific inquiry do not necessarily result from doing science per se (Bell et al. 2003). There also need to be frequent opportunities for reflection on NOS in the context of that authentic scientific research experience through journal writing and seminars (Schwartz et al. 2004). In their recent comparison of the epistemic beliefs of chemistry students and research chemists, Samarapungavan et al. (2006) come to the broadly similar conclusion that apprenticeship experiences are no automatic guarantee of epistemic development in students. They suggest that engaging students and expert researchers in conversation and reflection on epistemic issues related to research work will have a greater chance of success.

While apprenticeship or internship experiences offer enormous potential for enhancing NOS understanding, they create major logistical problems-especially in East Asian classrooms, where class size is routinely about 40 , and may be as high as 50 or 60 . Our response has been to present students with insight into authentic scientific practice through the development of a case study of contemporary scientific practice. A detailed review of 17 experimental studies of context-based or STS-oriented approaches at secondary school level by Bennett et al. (2007) indicates that such approaches have positive impact on students' understanding of scientific concepts and attitudes to science and school science, especially when attention focuses on recent scientific research and innovations. While none

\footnotetext{
${ }^{1}$ In a recent publication, Lederman (2006) sought to restrict use of the term nature of science to the characteristics of scientific knowledge (i.e., to epistemological considerations). In common with definitions adopted by Osborne et al. (2003) and Clough (2006), our conception of NOS encompasses the characteristics of scientific inquiry, the role and status of the scientific knowledge it generates, how scientists work as a social group, and how science impacts, and is impacted by, the social context in which it is located.
} 
of these studies focused specifically on NOS understanding, there is good reason to anticipate similarly favourable learning outcomes with respect to learning about science and scientific inquiry. Indeed, there are compelling arguments that critical consideration of socioscientific issues provides an ideal forum for students to deploy and develop their NOS understanding (Sadler 2004; Sadler and Zeidler 2005; Zeidler et al. 2005), especially when the issues are controversial (Kolstoe 2000; Oulton et al. 2004) or have strong personal relevance (Ryder 2002). Khishfe and Lederman (2006) remind us that although locating NOS teaching within controversial topics (in their case, discussion of global warming) can be effective, the essential requirement, as in internship and apprenticeship approaches, is that NOS teaching is both explicit and supportive of critical reflection. The case study described here focuses on an episode that was intensely personal for our students and had many controversial aspects. Moreover, the learning materials were designed to draw explicit attention to important NOS items and to encourage reflection.

By situating the learning of NOS and scientific inquiry within a specific episode in the 'contemporary history of science' we were able to meet Rudolph's (2000) call for teachers to acknowledge the context-dependency of scientific knowledge generation. We were also able to address the criticism by Elby and Hammer (2001) that the current consensual list of NOS items (see McComas and Olson 1998) is too general and broad. We concur with the claim of these authors that 'a sophisticated epistemology does not consist of blanket generalisations that apply to all knowledge in all disciplines and contexts; it incorporates contextual dependencies and judgments' (p. 565).

\section{SARS as a Context for Teaching NOS}

Encouraged by research findings on the potential of case studies for enhancing NOS understanding, we surmised that the well-publicised 'history' of the recent outbreak of the Severe Acute Respiratory Syndrome (SARS) would provide a powerful and familiar context for teaching about scientific inquiry. SARS attracted the attention of the whole world as scientists worked indefatigably to understand the biology of the disease and develop new diagnostic tests and new treatments. Throughout the crisis, extensive daily coverage by the media kept people up-to-date on the rapid development of scientific knowledge about SARS.

We saw the exceptionally rapid development of scientific knowledge about SARS as an opportunity to develop a set of instructional materials for enhancing teachers' and students' NOS understanding, particularly their understanding of contemporary scientific practice and its close inter-relationships with technology and society. We approached a number of scientists who had played a major role in the SARS research with a request to talk about their work. Our goal was to incorporate selected excerpts from the interviews into instructional materials to illustrate aspects of NOS and scientific inquiry. Our decision to utilise authentic experiences of practicing scientists working in a field closely related to the everyday lives of citizens was a response to Rudolph's (2003) assertion that, in any portrayal of science, 'at least two things should be considered: (1) what it is scientists actually do in the myriad research settings that exists, and (2) some vision of what the appropriate relationship should be between science and the public' (p. 76). It was our contention that the scientists' descriptions of how they conducted research during the SARS crisis would provide an authentic portrayal of real world science practice and the ways in which practice is related to societal concerns.

Instead of examining scientists' espoused views about NOS, as in some early studies by Kimball (1968), Pomeroy (1993) and Southerland et al. (2003), we made use of scientists' 
descriptions of their work to highlight for the audience of our teaching package how certain aspects of the scientists' work are related to various aspects of NOS and scientific inquiry. We concur with the recommendation by Glasson and Bentley (2000) that communicating descriptions of science and science practice provided by scientists can be an effective means of developing and enriching teachers' NOS understanding.

It is important to note that the scientists involved in the SARS research are working in a field of science that is under rapid development and change. Hence, their descriptions of investigative methods and comments on the ways in which their practices are influenced by society and technology may be surprising to some students and teachers. Indeed, the research has generated a substantial database for comparison with the list of NOS elements currently advocated for inclusion in school science curricula, as summarised by McComas and Olson (1998) from their analysis of a number of international science education standards documents. In particular, their descriptions have given us insight into some aspects of NOS in modern science that are in need of greater attention in the school science curriculum.

In this paper, we describe how we made use of the familiar and well-documented story of SARS and scientists' descriptions of their work and experience during the SARS epidemics to develop an instructional package for explicitly teaching NOS. We report on the prominent features of NOS and scientific inquiry identified in the scientific research on SARS and how these features were explicitly emphasised in our instructional package. The effectiveness of an explicit and reflective instruction using this instructional package in promoting student teachers' understanding of NOS and scientific inquiry is reported in a separate paper (Wong et al., in press).

\section{Interviews with Scientists}

To ascertain aspects of the nature of science and features of scientific endeavour exemplified in real world scientific research, we approached ten scientists who had played a key role in the advancement of research on SARS with a request to participate in our research and curriculum development project. We explained the purpose of the study, which was to demonstrate NOS aspects and features of scientific inquiry based on their experience during their fight against SARS. We also requested the scientists' permission to include video clips of their interview in our instructional materials. Nine scientists from five different research institutes in Hong Kong, mainland China and Canada kindly agreed to take part. Their specific contributions included identification of coronavirus as the pathogen of SARS, decoding of the genomic sequencing of the SARS-coronavirus, development of new diagnostic tests, and understanding of the transmission modes of SARS. Table 1 summarises each scientist's major contribution to the research on SARS and the geographical location of their research institute.

The nine scientists were sent the interview protocol given in Appendix A and a brief document outlining the ideas about science currently advocated for inclusion in school science curricula in different countries (McComas and Olson 1998; Lederman et al. 2002) upon their acceptance of our invitation, which was several weeks before their interview. This allowed them adequate time for recalling their research and other relevant experience during the SARS crisis. We also reminded the scientists of the targeted audience for the teaching package we would compile from their description of their work and requested them to answer the series of questions listed in Appendix A in 'laymen's terms'. This enabled an easy translation of relevant episodes of the interviews to be incorporated in the 
Table 1 Summary of scientists' major contributions to SARS research

\begin{tabular}{|c|c|c|}
\hline Scientists & Major contribution to the research on SARS & $\begin{array}{l}\text { Region of research } \\
\text { institute }\end{array}$ \\
\hline Dr. FL & $\begin{array}{l}\text { Led his research team in decoding the genomic sequence of the } \\
\text { SARS coronavirus }\end{array}$ & Hong Kong \\
\hline Dr. LP & $\begin{array}{l}\text { First scientist to obtain the partial genetic sequence of SARS- } \\
\text { coronavirus, a finding that contributed to the identification of } \\
\text { coronavirus as the causal agent of SARS }\end{array}$ & Hong Kong \\
\hline Prof. DL & $\begin{array}{l}\text { Led his research team in decoding the genomic sequence of the } \\
\text { SARS-coronavirus; developed a rapid diagnostic test; traced the } \\
\text { molecular evolution of the SARS coronavirus }\end{array}$ & Hong Kong \\
\hline Dr. AC & $\begin{array}{l}\text { Participated in decoding the genomic sequence of the SARS- } \\
\text { coronavirus }\end{array}$ & Hong Kong \\
\hline Dr. RC & Participated in the development of a rapid diagnostic test & Hong Kong \\
\hline Dr. KT & $\begin{array}{l}\text { Studied the genomic sequence and biology of selected genes of the } \\
\text { SARS-coronavirus }\end{array}$ & Hong Kong \\
\hline Prof. GZ & $\begin{array}{l}\text { Led the consortium which traced the molecular evolution of the } \\
\text { SARS-coronavirus during the course of the SARS epidemic in } \\
\text { China }\end{array}$ & Mainland China \\
\hline Prof. AS & $\begin{array}{l}\text { Described the epidemiological and clinical factors and outcomes of } \\
\text { a series of SARS cases; and proposed the mechanism for } \\
\text { transmission of SARS }\end{array}$ & Canada \\
\hline Dr. RS & Led a development program for a SARS vaccine & Canada \\
\hline
\end{tabular}

instructional materials. The interviews lasted for 30-180 min. All interviews were recorded, translated if required, and transcribed for analysis. Whenever there were uncertainties concerning scientists' remarks, clarification was sought through follow-up phone calls or emails.

\section{Data from Reports and Documentaries}

Local and international reports and documentaries produced by the media, together with research reports on SARS published in scientific journals, were perused and analyzed alongside the scientists' interview data. We were careful to ensure the reliability of the data obtained and selected from documentaries by using only sources with a sound track record for the quality of news reporting and production of documentaries. The information from each source was further triangulated against each other and against the detailed scientific development provided by scientists.

The documentary analysis and the inside story of the SARS research provided by the scientists gave the essential background details of a series of 'historical' events during the SARS crisis, as given in the second column of Tables 2-5.

\section{Identification of Prominent NOS Features in the Story of SARS}

Between July 2004 and February 2005 the authors held bi-weekly meetings to identify, discuss and agree on the NOS element(s) embedded in each historical event of the detailed account of the SARS story and associated scientific development. The embedded NOS 


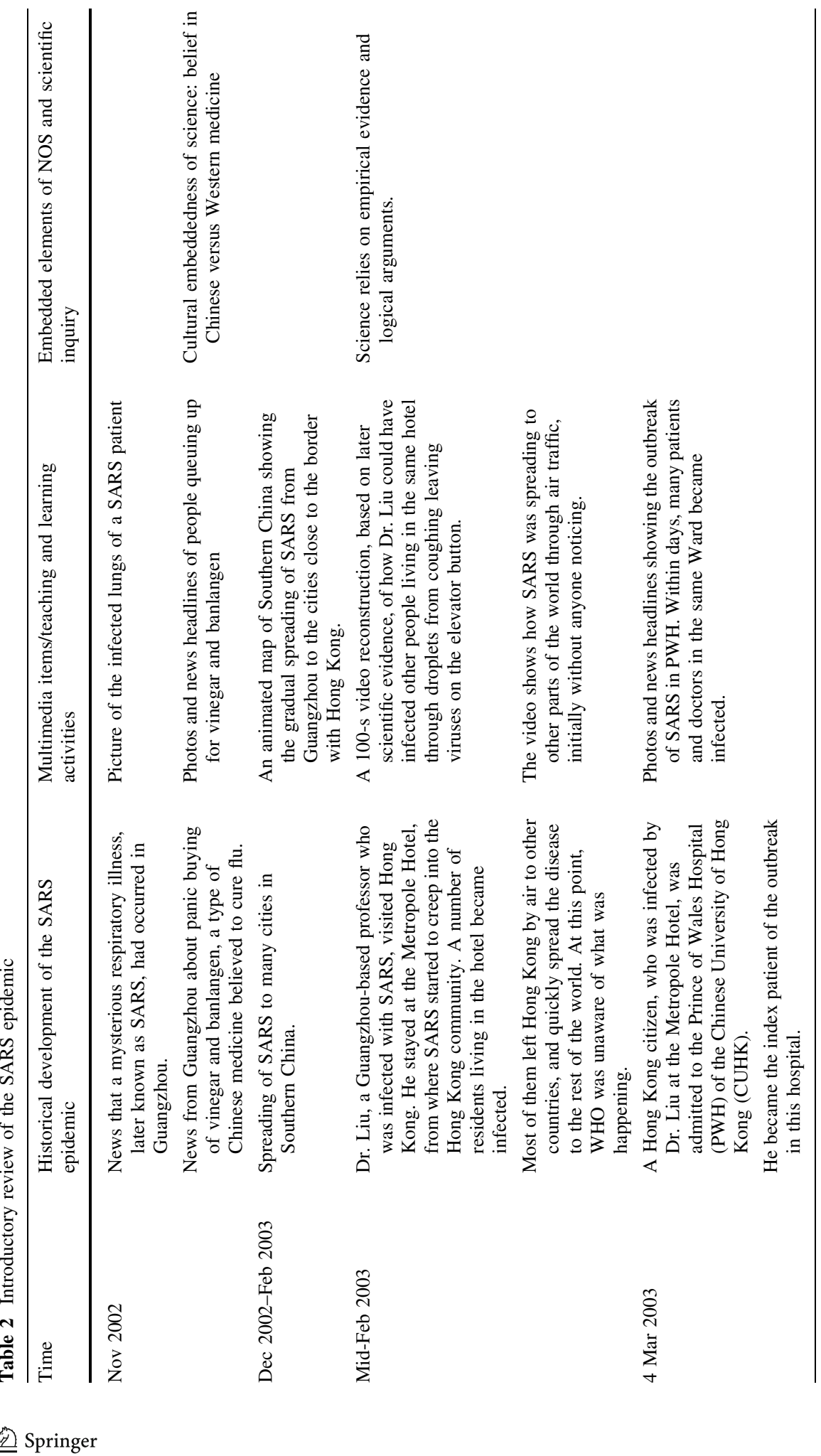




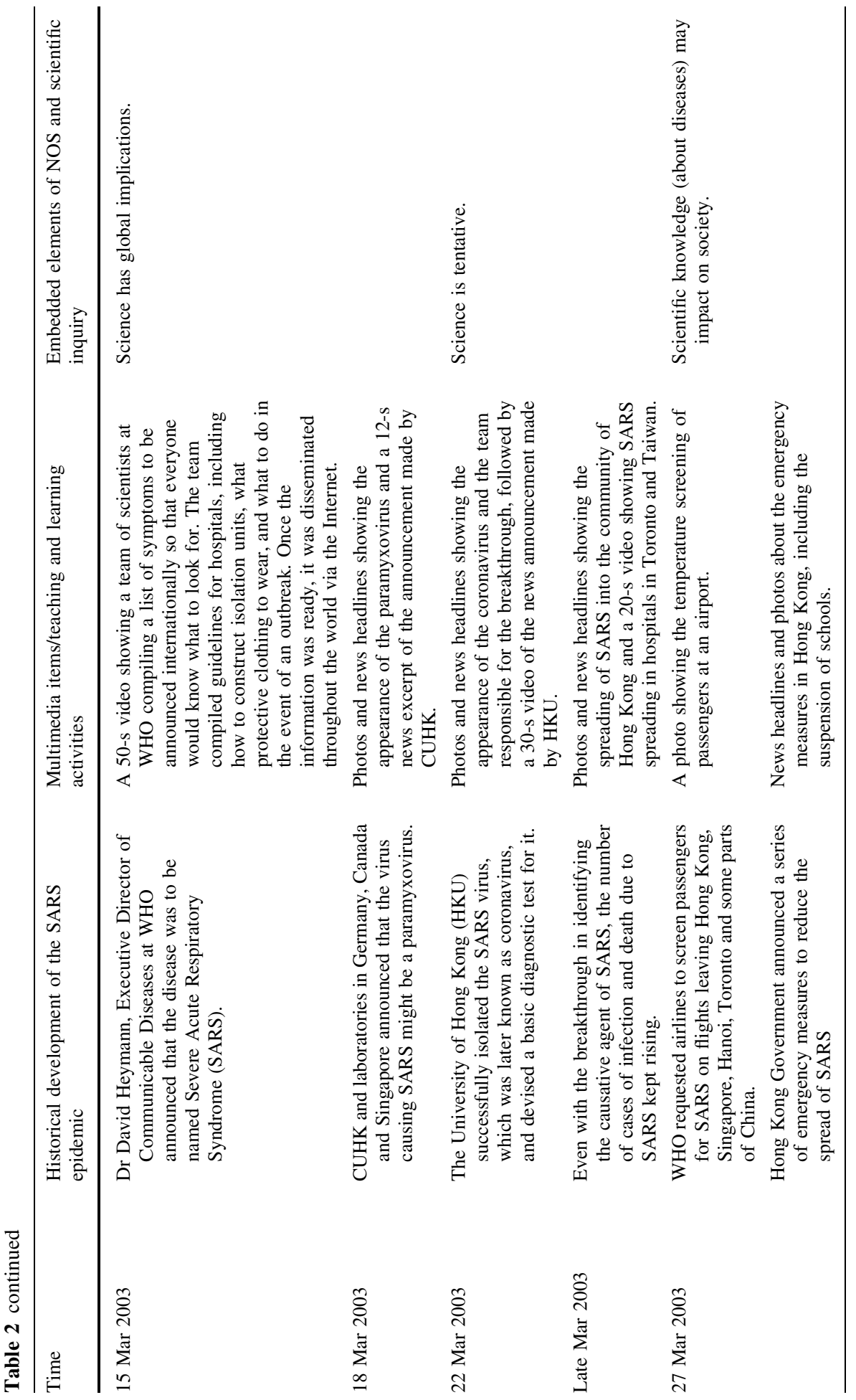




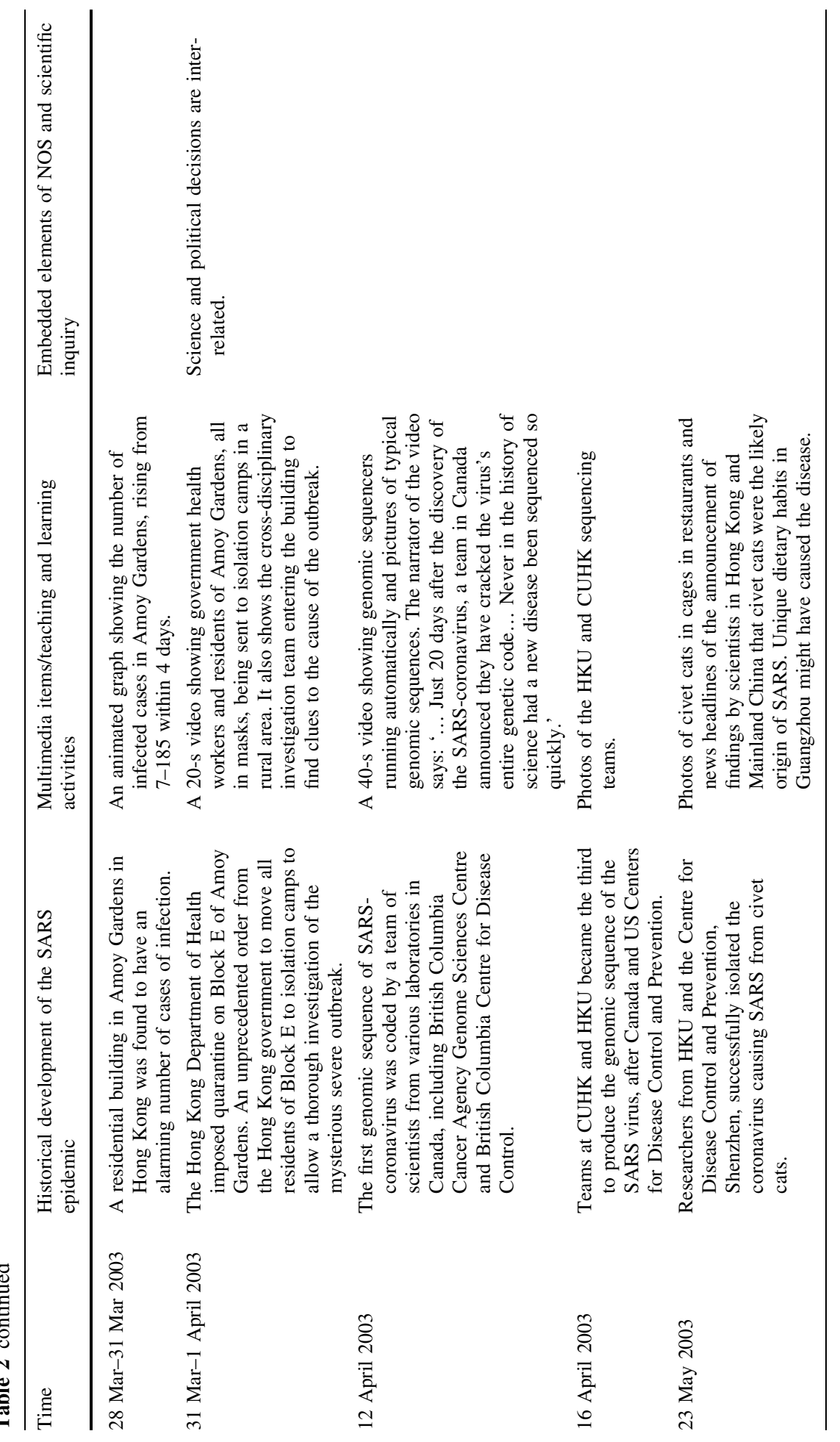




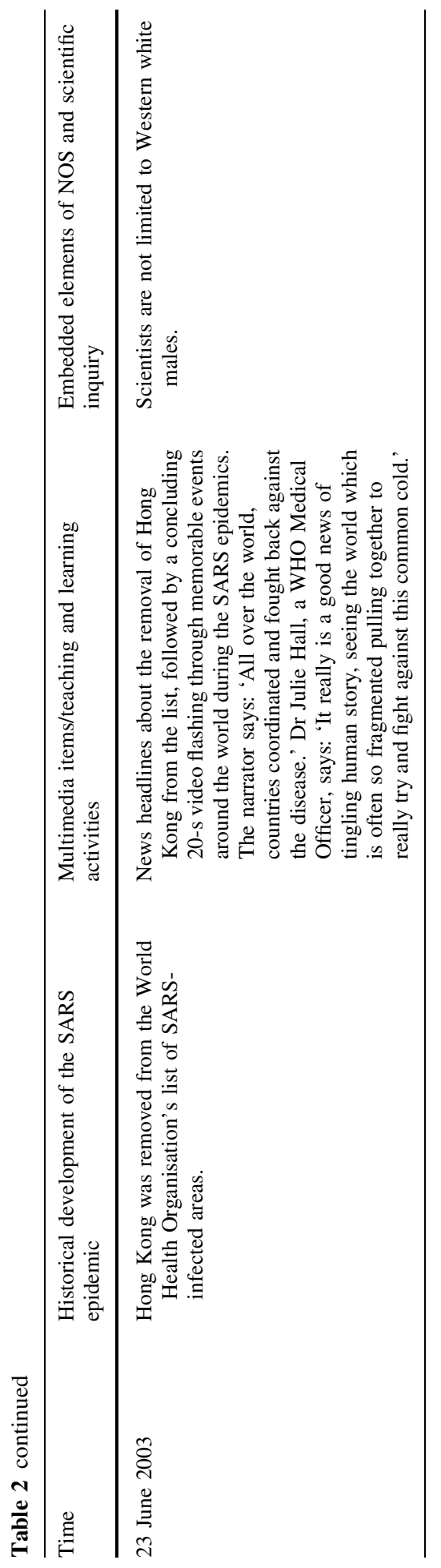




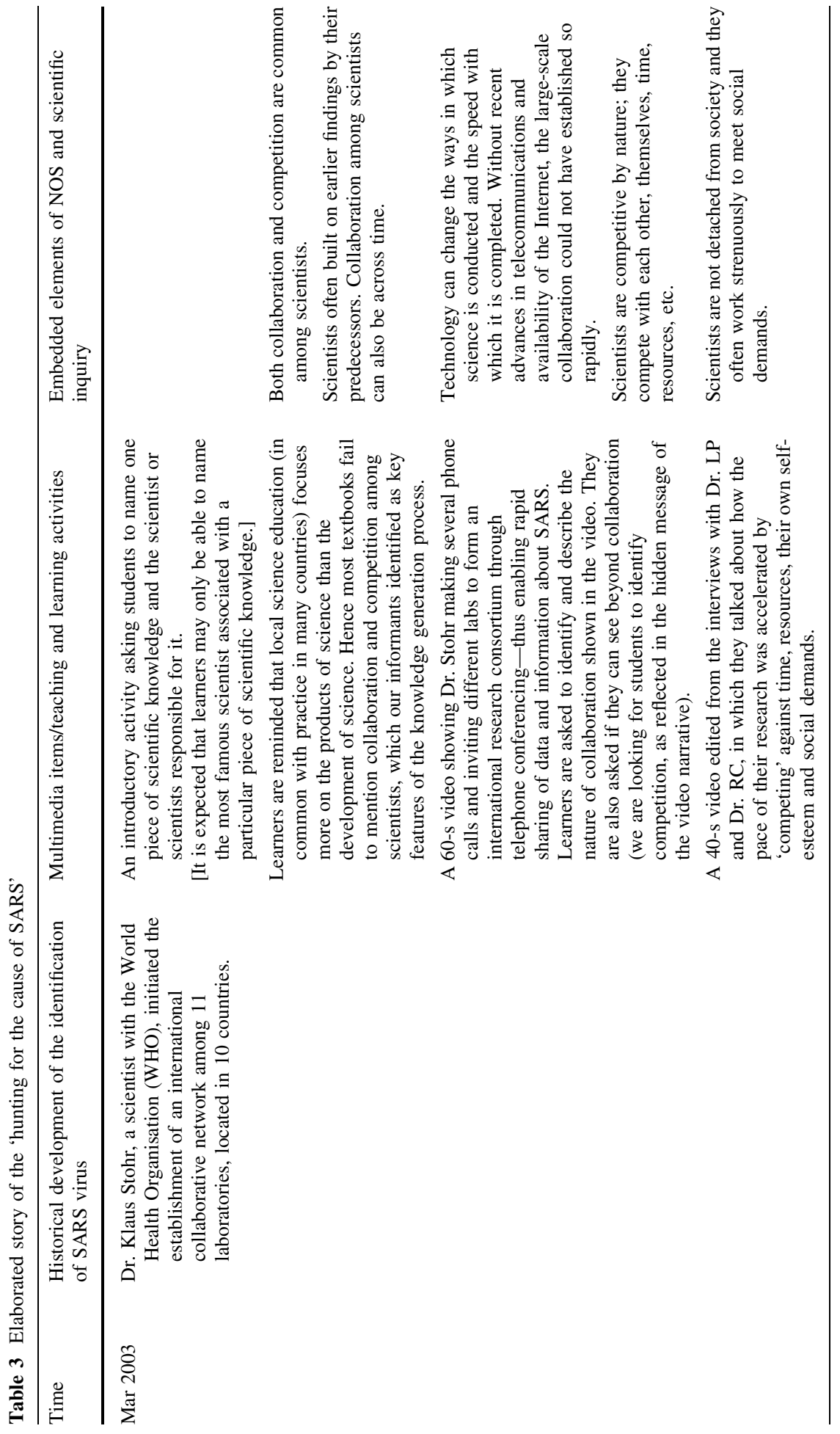




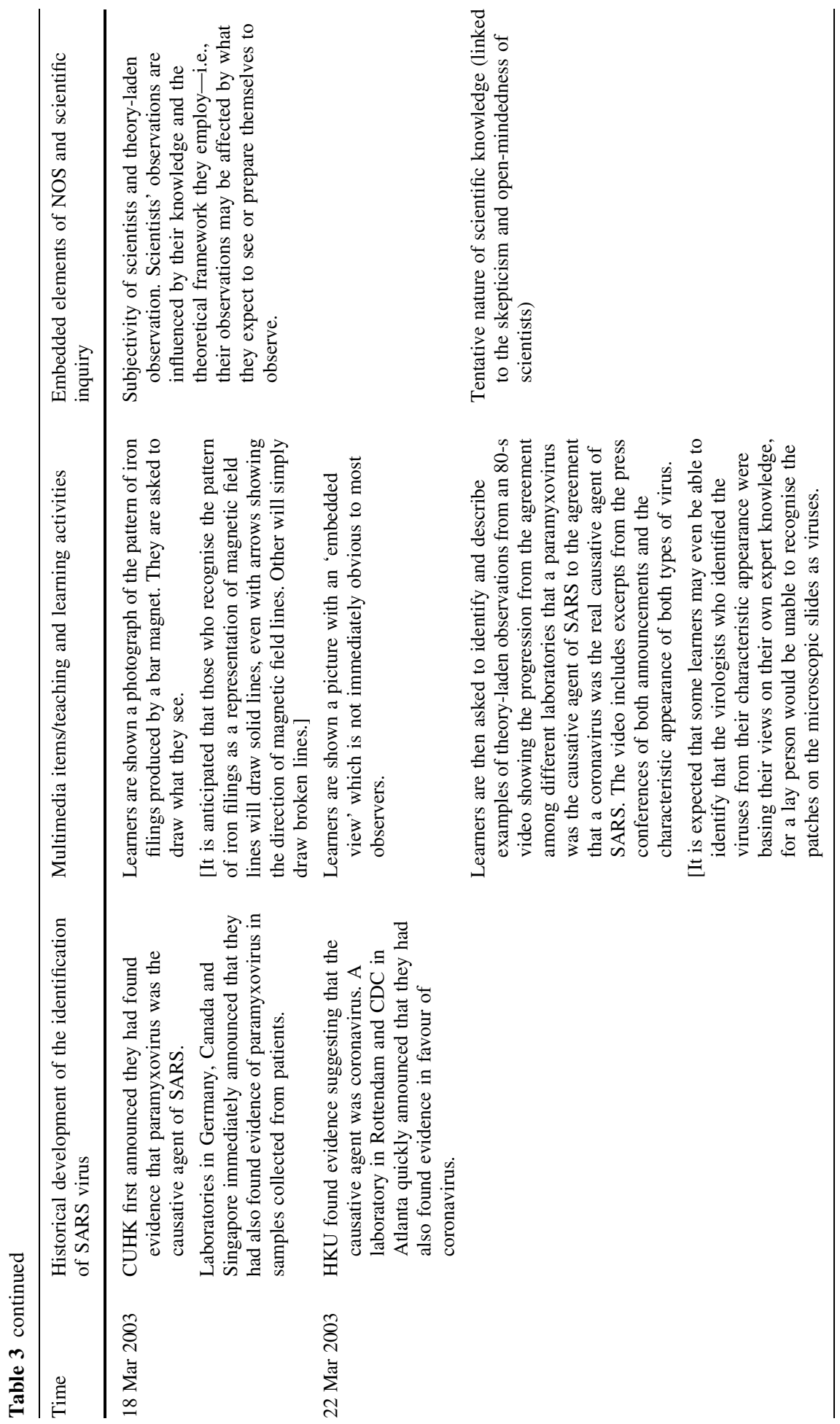




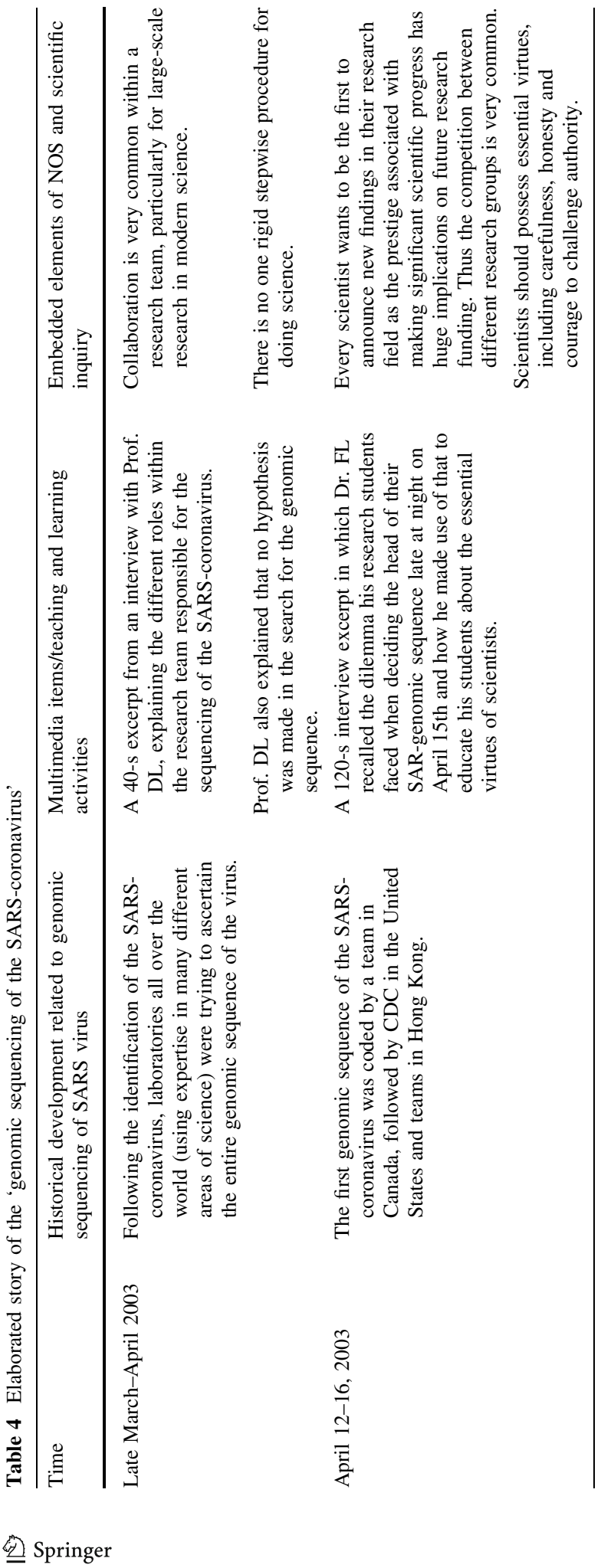




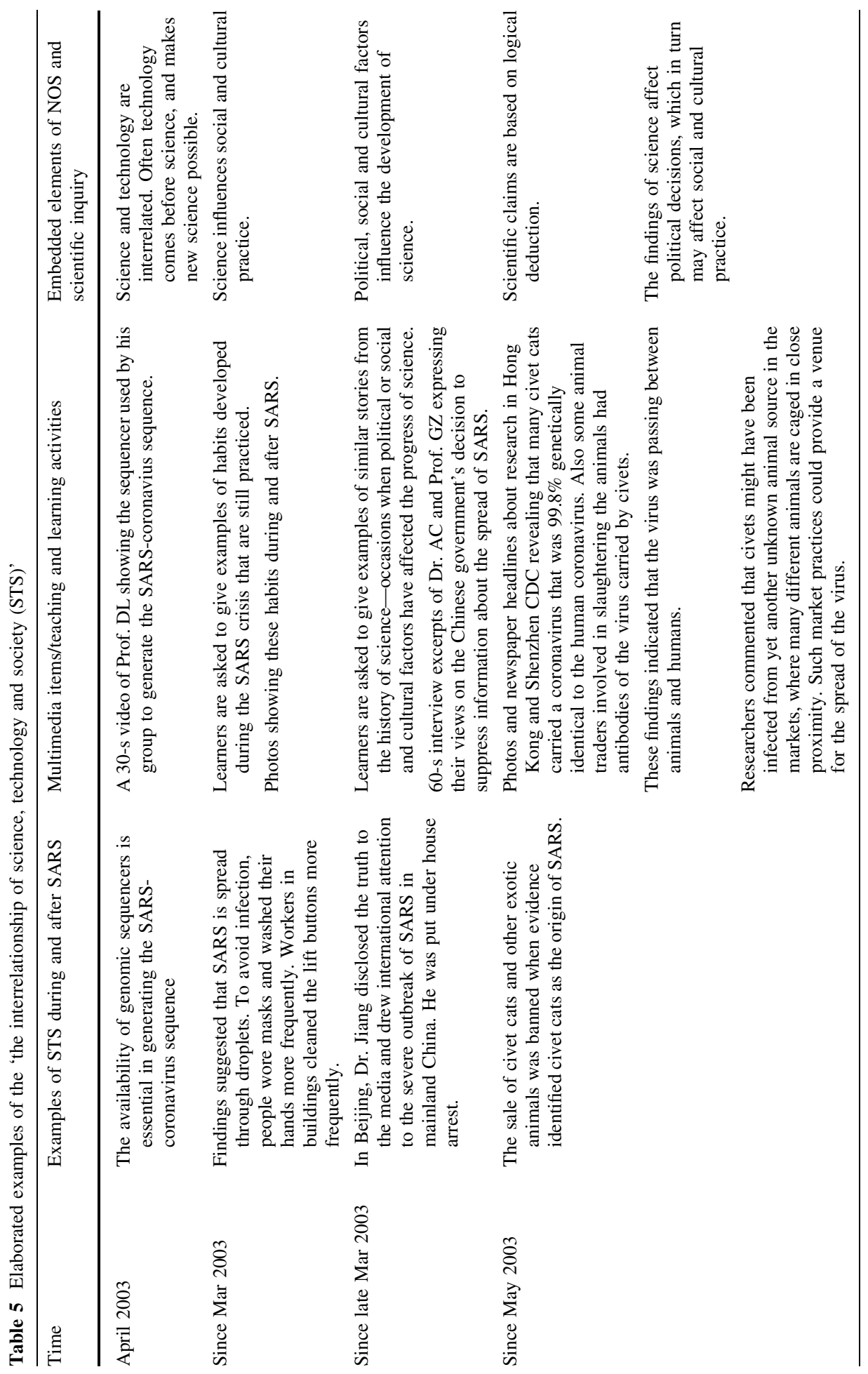


features in each historical event were first identified with reference to the list of advocated NOS features found in curriculum standards documents. Additional NOS elements were established to cover prominent features identified in the scientists' interviews and/or certain historical events of the scientific development of SARS that did not fall under the existing list NOS elements generated from curriculum standards documents (McComas and Olson 1998). Full agreement among authors on the finalised list was achieved.

The story of SARS provided some vivid illustrations of many of the NOS elements advocated for the school science curriculum (McComas and Olson 1998) - such as, the multiplicity of approaches used in scientific investigations, the theory-laden nature of observation and interpretation, the tentative nature of scientific knowledge, the dependence of scientific research on technological innovation, the impact of social and political factors on scientific research and the impact of scientific findings on social and cultural practice.

In addition, our data also revealed some NOS elements and features of real world scientific inquiry not commonly included in the school science curriculum. Notably, the need to combine and coordinate expertise in a number of scientific fields, the intense competition between research groups (suspended during the SARS crisis), the significance of affective issues relating to intellectual honesty and the courage to challenge authority, the pressure of funding issues on the conduct of research and the 'peace of mind' of researchers.

\section{Development of the Multimedia Teaching Package ${ }^{2}$}

These prominent features of scientific practice were contextualised within a series of critical 'historical' events during and after the SARS epidemic using video clips from relevant interviews with scientists and excerpts from news reports and documentaries. The video clips were edited and collated with photos, pictures and news headlines into a series of episodes describing the development of the SARS research and its impact on political decision-making, social and cultural practice and technological innovation. The product was a multimedia teaching package designed to explicitly emphasise particular elements of NOS and scientific inquiry through individual tasks, group discussion, and problem solving activities.

The teaching package begins with an introductory review of the history of the SARS epidemic designed to set the scene for a 4-h instructional experience. Table 2 lists the embedded elements of NOS and scientific inquiry and provides a brief description of the multimedia elements associated with each historical event. The introductory review, designed for presentation in a story-telling manner is intended to prompt learners in their attempts to identify aspects of science exemplified in the various episodes of the SARS story. This functions as a warm-up exercise, enabling learners to reflect on their current understanding of NOS.

Following the introductory review, the package elaborates three key components of the SARS story, namely (i) the hunt for the cause of SARS, (ii) the genomic sequencing of the SARS-coronavirus and (iii) the interrelationships among science, technology and society. Each component consists of a rich list of elements about NOS and scientific inquiry. In the following subsections, elements of NOS and scientific inquiry exemplified by episodes of the SARS story in the three key components are described in detail according to the order

2 An updated set of instructional materials can be accessed through the website http://learningscience. edu.hku.hk as training material under "teaching resources". 
of their appearance in the package. For each NOS element identified, we also describe learning and teaching activities designed to explicitly emphasise the element.

\section{NOS Elements as Reflected in the Hunt for the Cause of SARS}

Significant episodes in the hunt for the cause of SARS, the relevant features of NOS exemplified, and the elements included in the multimedia package and learning activities, are summarised in Table 3.

\subsection{Collaboration and Competition among Scientists}

The traditional textbook portrayal of scientists as solitary heroes who make great scientific discoveries fails to reflect the collaborative and competitive nature of real-world scientific practice. In this key component, we included a video clip from the program, SARS: the True Story, produced by the British Broadcasting Company (Higgins and Learoyd 2003) which describes how Dr. Klaus Stohr, a scientist with the World Health Organisation (WHO), initiated the establishment of an international collaborative network, utilizing telephone conferencing, among 11 laboratories spread across 10 countries. This occurred immediately after the WHO became aware of the seriousness of the epidemic.

We knew that it was a race against time, so we had to find very quickly the pathogen, the causative agent for this disease. (Dr. Klaus Stohr)

He contacted the world's top microbiologists, from America to Beijing and asked them, just once to work together... (Jack Fortune-Narrator)

These scientists are competitive by nature but we called up 11 laboratories in 10 countries... (Dr. Klaus Stohr)

$24 \mathrm{~h}$ later, all the labs had agreed to forgo their rivalries and collaborate. For the first time in history, the full force of the world's scientific might was united. (Jack Fortune-Narrator)

In this episode, we will first draw learners' attention to the fact that collaboration is common in real-world science practice when scientists from different groups see a common interest to be exploited or concern to be addressed. We will also highlight the amazingly short time for the establishment of this large-scale collaboration on SARSsomething that was only possible because of modern modes of communication, bringing out the interconnection of scientific and technological advancement. We will then draw teachers' attention to the hidden message in the above narrative. The phrases '...just once to work together' and 'for the first time in history...' reflect the highly competitive stance among different research groups that is characteristic of normal situations. Collaboration among scientists is included in many of the curriculum standards but has only recently been mentioned in (a few) science textbooks. Competition and funding issues in the scientific community is almost entirely absent from both curriculum standards and school science textbooks.

In our interview with the nine scientists, we were told repeatedly that scientists are constantly 'competing' with all manner of constraints, lack of time and limited resources, and with other research groups working on similar projects. In consequence, we included an excerpt of our interview with Dr. LP that emphasises this particular message. 
Competition isn't just with other teams but also with time... The fact that science improves so quickly is all because scientists compete with each other, with time... and their own.

We also included an interview with Dr. RC conducted by a local television company during the most serious and critical moment of the SARS crisis, when many doctors in her hospital were being infected. She was almost in tears as she shared her frustration and helplessness.

After the two colleagues passed away, some of our colleagues are in a life-threatening situation. We are now receiving phone calls if our research can give immediate help. We need to work on urgent requests... hoping that we can help stop or reduce the rate of infection... We have become so stressed out... We also wish earnestly that we can lessen the harm and have been asking ourselves "how come our research still can't be any help?"

The feelings expressed by Dr. RC reinforced the need for scientists to compete against time and highlighted the pressure on them to meet social demands. Her distress and expressions of concern demonstrate that scientists are not isolated from the social environment in which they work. Another purpose for including this video clip is the need to address the common stereotypical image that scientists are always men, often weird looking and frequently detached from society (Chambers 1983). Dr. RC's interview, together with several references to other female scientists in our teaching package, help underline the message that women can also be good scientists.

\subsection{Objectivity of Scientists and Theory-laden Observation}

Although it is now over 20 years since Hodson (1986) urged teachers to acknowledge the theory-laden nature of scientific observation, it is still only rarely elaborated in science textbooks, and is often overlooked by both teachers and students.

The elaborated story of the hunt for the causative agent of SARS was infused with several examples of the theory-laden nature of scientific observation. The historical account of the 'hunt' will be used as an exercise to probe the understanding of learners on this aspect of nature of science. We will show a video clip showing that immediately following the announcement on 18 March 2003 by a group of scientists from Hong Kong and Germany that the virus causing SARS was paramyxovirus, other research groups around the world quickly announced that they had also found evidence that paramyxovirus was the causative agent of SARS. However, only a few days later, on 22 March 2003, another group of researchers in Hong Kong announced that further evidence showed that coronavirus, rather than paramyxovirus, is the causative agent of SARS. Immediately after this announcement, several laboratories, including Rotterdam, Frankfurt and the Center for Disease Control and Prevention (CDC) in Atlanta, also confirmed the coronavirus theory. This episode illustrates the theory-laden nature of observation and shows how scientists' expectations or predictions influence what they see and how they interpret the data. Acknowledgement of the biased observation of data is in stark contrast to the usual school science curriculum portrayal of scientists as objective and impartial in interpreting data.

The video clips of news reports about the rapid development of knowledge of the cause of SARS were organised in a sequential manner to explicitly draw teachers' attention to 
the agreement of other laboratories directly after a laboratory announced new findings. We also made use of a video clip showing the appearance of the coronavirus as observed by John Nicholls, the pathologist who first recognised that the halo of dots surrounding the virus was strongly suggestive of a coronavirus, as another example of theory-laden observation. We made the point that because they lack the expert knowledge of the appearance of various viruses, lay people would be unable to identify the crown-like coronavirus.

\subsection{Tentativeness of Scientific Knowledge}

We used the search for the identity of the SARS-virus to emphasise the tentativeness of scientific knowledge. All nine scientists considered revision, modification and refutation of existing scientific knowledge to be commonplace in their work. Indeed, their everyday task is not to maintain or safeguard current scientific knowledge but to move science forward by introducing new data and ideas, and providing new frameworks to interpret existing data from different perspectives. The scientists in our study all recognised the theory-laden nature of observation and noted that there can be different interpretations of the same set of data because scientists utilise their favoured theories. Disagreements and arguments among scientists are common and an inevitable stage in the journey towards more established and well-accepted scientific knowledge. The initial acceptance of the paramyxovirus as the causative agent of SARS, and its rapid replacement by the coronavirus as a consequence of new evidence and subsequent empirical tests based on the Koch's postulation, was used to illustrate the tentativeness of science. We also linked tentativeness to some essential characteristics of good scientists-skepticism and openmindedness.

\section{NOS Elements as Reflected in the Story of the Genomic Sequencing}

Prominent features of NOS identified in the elaborated story of the genomic sequencing of the SARS-coronavirus, and items included in the design of the multimedia component to explicitly highlight these features, are summarised in Table 4.

\subsection{Large-scale Research and Necessity for Collaboration}

Both Dr. FL and Prof. DL led large research teams to sequence the SARS-coronavirus. During his interview, Prof. DL described the different stages involved in the genomic sequencing of the SARS-coronavirus and the need for a range of scientific expertise.

In doing genomic sequencing, our working pattern was like that in a factory. Researchers were assigned different tasks. Some were in charge of data collection, e.g. some studied the anamesis such as when the patient got infected, when the patient was hospitalised and when the patient got his first fever. Some were responsible for cultivating the virus. Some were responsible for studying the gene of the cultivated virus and extracting the RNA. Another group then turned the RNA to DNA. The next group would then sequence the DNA, whereas another group analysed the sequence. 
Research in molecular biology often involves the deployment of skills and expertise in a series of highly focused areas. Dr. KT illustrated it using an analogy with shoe-making. In the old days, the whole shoe was produced by a shoe-maker, but in modern times each stage of production is completed by a group of workers who then pass it on to the next group along the production line. The scale of research in molecular biology has grown so much that it has become almost impossible for a researcher to be skilful in all tasks. Thus collaboration within a research team is essential. To be successful, scientists also need to be aware of work done by other groups and be willing to use it to advance their own thinking.

\subsection{More than One Scientific Method}

One of the most pervasive myths of science is the notion that a common series of steps is adopted by all research scientists in all situations (McComas 1998). This is probably a direct consequence of the 'scientific method' occupying such a prominent position in the introductory chapters of science textbooks encountered by students at the very outset of their formal learning in science. Many students and teachers consider that making a hypothesis is an essential component of this stepwise generation of scientific knowledge (Watson et al. 1999). However, the interview with Prof. DL concerning the decoding of the genomic sequence of the SARS-coronavirus provided a clear counter example:

After we knew that coronavirus was the causative agent of SARS, we did the sequencing, and no hypothesis was needed during this process, we just sequenced it... Right, like the human genome project which sequences our three billion base pairs, it's not hypothesis-driven.

This type of knowledge generation without making hypotheses is increasingly common in newer fields of science such as molecular biology. With recent advances in technology, most of the tedious data collection is now done by high-speed computers, and data collection which previously took months to complete now only takes minutes. The much reduced data generation time makes meticulous hypothesizing and theorizing before actual experimenting less important than in the past. Scientific investigations in which data are obtained first and then interesting problems are identified by 'data mining' have become much more common in recent years.

\subsection{Competition and Funding Implications}

During the interview with Dr. FL, about a year after the SARS crisis, the tension and excitement generated at the time when his research team was competing to be the first research group to announce the entire sequence of SARS-coronavirus was still very much in evidence. This interview episode reinforces the point that competition among scientists, particularly from different research groups, is a significant aspect of science and should no longer be ignored in the school curriculum. Indeed, many of the scientists we interviewed mentioned that their greatest pressure and concern in their research work comes from the limitations of resources and funding that might compromise their capacity to compete with other research groups. Some Hong Kong scientists expressed frustration about the huge difference in the number of genomic sequencers between their laboratories and the laboratories in Canada that announced the first sequence of SARS-coronavirus. 


\subsection{Honesty and Courage to Challenge Authority}

Dr. FL's account of the dilemma faced by his research team before disseminating their findings about the sequence of SARS-coronavirus on the WHO network for public scrutiny reflects an interesting phenomenon: claims made by prestigious research institutions are much more likely to be accepted by other scientists than claims emanating from elsewhere. The crucial point is that the Hong Kong team's data conflicted with the data accumulated by the highly prestigious Center for Disease Control and Prevention (CDC) of United States.

Around 10 p.m., it was the last base pair...my research students didn't know what to do... In the US sequence, the first base pair of the head was an "A", but ours started with a "T". ...my students asked me if we should put an "A" or a " $T$ ". When that student asked me, I thought of one thing, this was one of the best chances for me to share with my students one of the important points, that is "data don't lie". I stopped everyone in the team from working and asked them what we should do as the CDC sequence started with an "A" and ours started with a "T". No one answered, as Hong Kong students are usually shy... So I told them to take out all the raw data, and we not only did a duplicate or a triplicate... Over and over again, we found that it was a "T", so I said, "Do we still have any doubt about whether to put an "A" or a "T"?". And one student was really funny, he said, "Fred, CDC could not be wrong." And I said, "Well, I don't care much about whether CDC could be wrong or not, our research confirmed over and over again that we started with a " $T$ " instead of an "A", so we should enter a "T" instead of an "A"." At about 11:30 p.m., we uploaded our sequence.

This decision of Dr. FL's group to hold firmly to their own data instead of suppressing them in favour of what the prevailing authority claimed is enormously valuable in emphasizing to learners the importance of scientists being honest and not submitting to authority. Several of the video interviews with scientists included in our instructional package reveal other desirable attributes for scientists, including being meticulous, organised, sensitive to the need to collect and record data accurately, and being aware of the theory-laden nature of observations and interpretation of data.

\section{Inter-relationships among S-T-S as Reflected in the SARS Story}

There are numerous examples of the interrelationships among science, technology and society in the SARS story. The events, the NOS elements exemplified, and the learning and teaching activities included in the multimedia package are summarised in Table 5.

\subsection{Inter-relationship between Science and Technology}

The science curriculum often portrays technology as no more than the application of science, and many teachers and students hold the view that 'science comes first and technology follows'. The following comment by Prof. DL provides an illustration of the dynamic interrelationship of science and technology. 
It is scientific knowledge about DNA structure and the DNA sequencing reaction which leads to the production of DNA sequencers... With the DNA sequencers, a DNA sequence can be obtained in a much reduced time... leading to the cracking of the SARS-coronavirus... and recently the entire human genome.

He proceeded to state that contemporary research in molecular biology relies extensively on advanced technology. Sadly, laboratories with inadequate funding for the acquisition of advanced equipment find it difficult to compete at the frontier of scientific research.

Events during the SARS epidemic illustrate the impact of scientific findings on technological development. To prevent the spreading of the SARS disease, WHO identified and disseminated a list of symptoms of SARS in mid-March 2003, and requested stringent screening of passengers' body temperature at airports in the infected places, including Hong Kong, Singapore, Toronto and some cities in Mainland China. These guidelines prompted the development of high-speed body temperature sensors. Hand-held infra-red temperature sensors and sophisticated thermal imagers were installed in these airports by late March 2003, and are still in use today.

\subsection{Interactive Influence between Science and Political Decisions}

There are several episodes in the instructional package that describe the influence of scientific findings about SARS (e.g. the transmission mode through aerosol droplets) on political decisions during and after the epidemic. For example, the unprecedented decision of the Hong Kong government to suspend all schools when many parents sought to prevent their children from being infected by keeping them at home. Another unprecedented government decision was made in response to medical statisticians identifying an alarmingly high infection rate among residents in a particular residential building (Amoy Gardens). The decision was taken to isolate the building and move all residents to a rural camp site to permit a thorough and unimpeded examination of the building. The sale of civet cats was banned after researchers announced evidence which pointed to civet cats as the source of the original SARS cases in Guangdong province. When Dr. RC was talking about the data leading to the ban on eating civet cats, she put particular emphasis on the social impact of research findings.

The data [including early SARS patients were mostly restaurant workers who handle wild animals and serve exotic food like civet cats; civet cats carried a coronavirus almost identical to human coronavirus] directly affected the business of merchants selling exotic animals. These people may not even have learnt science at all in their life but their lives have been heavily affected by science.

Sadly, there were also some occasions when scientific research on SARS was impeded by political decisions. In mainland China, in a misguided effort to prevent widespread panic, strenuous efforts were made to conceal the true extent of the epidemic. When Dr Jiang Yanyong exposed the cover-up in a letter to a Beijing television station and Time magazine, he was arrested and detained. Dr. AC commented on this incident as follows:

In Mainland China, when the government said there were no cases of SARS at the beginning of the epidemic... how could the scientists in China do research on samples collected from the SARS patients there if there were no cases?... Certainly scientific research is oftentimes controlled by the will of the government. 
Professor GZ, a molecular biologist, said that he could see 'both sides of the coin' with regard to the delay in announcing details of the SARS infection in China. In an interview conducted 18 months after the SARS crisis was over, he commented:

We have learnt from SARS that if the government wants to keep this kind of thing secret, it's not good... The government didn't want to release information in the early stages because they were afraid that the media was going to make the situation worse...

Now the WHO doesn't think SARS is a very severe disease. Even if SARS comes back, the WHO will treat it very calmly... Media may sometimes be dangerous in causing over-reaction among the people... and that probably would influence the research and also the medical treatment... It's really not necessary to panic, but the media didn't know that...I think we have to educate the government, the media and the people...

Clearly, Professor GZ holds the view that irrational panic can be suppressed by educating the general public and promoting a better understanding of science and the nature of science.

\subsection{Interactive Influence between Science and Social and Cultural Practice}

In Hong Kong, many social practices developed during the crisis in response to scientific findings about the transmission of SARS are still evident. For example, face-masks are worn when people fall ill or when they visit hospitals; lift buttons are cleaned more frequently; two pairs of chopsticks, one for eating and the other for picking up food from

shared dishes, are provided by most restaurants. In other words, science is seen to have had a profound influence on day-to-day social and cultural practices.

We have also noted some examples of well-established social and cultural practices influencing people's responses to the possibility of SARS infection. In western countries or regions with a strong western influence like Hong Kong and Singapore, patients were treated with Western medicine. In contrast, people in Mainland China searched for traditional Chinese medicine and traditional ways of preventing SARS infection. For example, it was widely believed that boiling and vaporizing vinegar into the surroundings may reduce the chance of being infected. In our package, photos showing people queuing up for Chinese medicine and vinegar in Mainland China are compared with photos of people in regions under Western influence being treated by Western medicines such as Ribavirin and steroids. Unfortunately, many SARS patients who were treated by the latter means suffered from long-term side effects.

\section{Significance of the Study}

This investigation on the work of scientists on the SARS research provides empirical evidence of some prominent features of NOS in contemporary scientific fields which have not been adequately emphasised in the school science curriculum. This supports the important message by Rudolph (2000) that educators, curriculum designers and teachers should be open enough to accept that there is no single preferred or informed NOS framework which is static with time. Rather, NOS is as tentative as scientific knowledge itself (Lederman 1995). We suggest that teachers, curriculum planners and science 
educators engage in reconsideration of the aspects of NOS included in the school science curriculum in order to reflect more fully the practice of science in the 21 st century. In particular, we would like to see much more emphasis on the need to combine and coordinate expertise in diverse scientific fields, the intense competition between research groups, the significance of affective issues and funding constraints on the conduct of research, and the complex interactions within the social, cultural and political milieu in which scientific practice is located.

We hope that our efforts in 'turning crisis into opportunity' through identifying prominent NOS aspects in the story of SARS, and designing learning activities to explicitly teach about these aspects, can encourage others to capitalise on examples of contemporary scientific inquiry in real-world practice. Contemporary examples adjusted to fit the level of targeted students possess several instructional advantages. For instance, when scientists who have made a key contribution to the advancement of the field talk about the 'inside stories' and narrate first person experiences, there is a much enhanced sense of authenticity and greater interest among students. The rapid and accelerating pace of scientific development ensures that there is no shortage of intriguing stories of authentic scientific inquiry to keep our students captivated for years to come.

Acknowledgement The authors gratefully acknowledge the nine scientists who kindly devoted their precious time to be our informants. The research reported in this paper was supported by a Competitive Earmarked Research Grant of the Research Grant Council of Hong Kong SAR, China (Project No: HKU 7483/04H).

\section{Appendix A}

Questions of the Semi-structured Interview with the Scientists

1. Could you describe the findings and contributions of you and your research group in the battle against SARS in the past few months?

2. Could you describe the research methods that you have used to achieve the findings and contributions you have just described?

3. What are the main concerns and pressures you faced during SARS research?

4. Could you comment on whether each of these elements has been demonstrated in your research work on SARS? If yes, please give a concrete example. [The scientists were provided with a list of NOS elements compiled with reference to the analysis of school curriculum documents by McComas and Olson (1998) and Lederman et al. (2002)].

5. Are there any other additional elements that you have experienced which are not included in this list?

6. In your opinion, which elements of NOS should be taught to school students?

\section{References}

Abd-El-Khalick F, Lederman NG (2000) Improving science teachers' conceptions of nature of science: a critical review of the literature. Int J Sci Educ 22(7):665-701

American Association for the Advancement of Science (1993) Benchmarks for science literacy. Oxford University Press, New York

Bell RL, Blair LM, Crawford BA, Lederman NG (2003) Just do it? Impact of a science apprenticeship program on high school students' understandings of the nature of science and scientific inquiry. $\mathrm{J}$ Res Sci Teach 40(5):487-509 
Bennett J, Lubben F, Hogarth S (2007) Bringing science to life: a synthesis of the research evidence on the effects of context-based and STS approaches to science teaching. Sci Educ 91(3):347-370

Chambers DW (1983) Stereotypic images of the scientist: the draw-a-scientist-test. Sci Educ 67(2):255-265

Clough MP (2006) Learners' responses to the demands of conceptual change: considerations for effective nature of science instruction. Sci \& Educ 15(5):463-494

Council of Ministers of Education, Canada (1997) Common framework of science learning outcomes. CMEC Secretariat, Toronto

Elby A, Hammer D (2001) On the substance of a sophisticated epistemology. Sci Educ 85(5):554-567

Finson KD (2002) Drawing a scientist: what we do and do not know after fifty years of drawing. School Sci \& Maths 102(7):335-345

Glasson GE, Bentley ML (2000) Epistemological undercurrents in scientists' reporting of research to teachers. Sci Educ 84(4):469-485

Higgins J, Learoyd S (Producer) (2003, May 29) SARS: the true story. [Television broadcast]. BBC Worldwide, North Sydney, NSW

Hodson D (1986) The nature of scientific observation. School Sci Rev 58(242):17-28

Irwin AR (2000) Historical case studies: teaching the nature of science in context. Sci Educ 84:5-26

Khishfe R, Lederman N (2006) Teaching nature of science within a controversial topic: integrated versus non-integrated. J Res Sci Teach 43(4):395-418

Kimball ME (1968) Understanding the nature of science: a comparison of scientists and science teachers. J Res Sci Teach 5(2):110-120

Kolstoe SD (2000) Consensus projects: teaching science for citizenship. Int J Sci Educ 22(6):645-664

Lederman NG (1992) Students' and teachers' conceptions of the nature of science: a review of the research. J Res Sci Teach 29(4):331-359

Lederman NG (1995) Suchting on the nature of scientific thought: are we anchoring curricula in quicksand? Sci \& Educ 4:371-377

Lederman NG (2006) Research on nature of science: reflections on the past, anticipations of the future. Asiapacific forum on science learning and teaching. Available on-line at: http://www.ied.edu.hk/apfslt/ v7_issue1/foreword/index.htm

Lederman NG, Abd-El-Khalick F, Bell RL, Schwartz RS (2002) Views of nature of science questionnaire: toward valid and meaningful assessment of learners' conceptions of nature of science. J Res Sci Teach 39(6):497-521

Lin H-S, Chen C-C (2002) Promoting preservice chemistry teachers' understanding about the nature of science through history. J Res Sci Teach 39(9):773-792

McComas WF (1998) The principal elements of the nature of science: dispelling the myths. In: McComas WF (ed) The nature of science in science education: rationales and strategies. Kluwer, Dordrecht, pp 53-70

McComas WF, Olson JK (1998) The nature of science in international science education standards documents. In: McComas WF (ed) The nature of science in science education: rationales and strategies. Kluwer, Dordrecht, pp 41-52

Millar R, Osborne J (eds) (1998) Beyond 2000: science education for the future. King's College, London

Moss DM, Abrams ED, Robb J (2001) Examining student conceptions of the nature of science. Int J Sci Educ 23(8):771-790

Osborne J, Collins S, Ratcliffe M, Millar R, Duschl R (2003) What “ideas-about-science" should be taught in school science? A Delphi study of the expert community. J Res Sci Teach 40(7):692-720

Oulton C, Dillon J, Grace MM (2004) Reconceptualizing the teaching of controversial issues. Int J Sci Educ 26(4):411-423

Pomeroy D (1993) Implications of teachers' beliefs about the nature of science: comparison of the beliefs of scientists, secondary science teachers, and elementary teachers. Sci Educ 77(3):261-278

Rudolph JL (2000) Reconsidering the 'nature of science' as a curriculum component. J Curricul Stud 32(3):403-419

Rudolph JL (2003) Some thoughts on portraying epistemology in today's classrooms: a reply to Garrison. Sci Educ 87(1):90-93

Ryder J (2002) School science education for citizenship: strategies for teaching about the epistemology of science. J Curricul Stud 34(6):637-658

Sadler TD (2004) Informal reasoning regarding socioscientific issues: a critical review of research. J Res Sci Teach 41(5):513-536

Sadler TD, Zeidler DL (2005) Patterns of informal reasoning in the context of sociscientific decision making. J Res Sci Teach 42(1):112-138

Samarapungavan A, Westby EL, Bodner GM (2006) Contextual epistemic development in science: a comparison of chemistry students and research chemists. Sci Educ 90:468-495 
Schwartz RS, Lederman NG, Crawford BA (2004) Developing views of nature of science in an authentic context: an explicit approach to bridging the gap between nature of science and scientific inquiry. Sci Educ 88:610-645

Southerland SA, Gess-Newsome J, Johnston A (2003) Portraying science in the classroom: the manifestation of scientists' beliefs in classroom practice. J Res Sci Teach 40(7):669-691

Watson R, Goldsworthy A, Wood-Robinson V (1999) What is not fair with investigations? School Sci Rev 80(292):101-106

Wong SL, Kwan J, Hodson D, Yung BHW (in press) Turning crisis into opportunity: enhancing student teachers' understanding of nature of science and scientific inquiry through a case study of scientific research in Severe Acute Respiratory Syndrome. Int J Sci Educ

Zeidler DL, Sadler TD, Simmons ML, Howes EV (2005) Beyond STS: a research-based framework for socioscientific issues education. Sci Educ 89(3):357-377

\section{Author Biographies}

Siu Ling Wong is an Assistant Professor, in the Division of Science, Mathematics and Computing in the Faculty of Education at The University of Hong Kong. She received her B.Sc. from The University of Hong Kong and her Ph.D. from the University of Oxford. Her research interests include promoting teachers' and students' understanding of nature of science and scientific inquiry, physics education, teacher professional development.

Jenny Kwan is a PhD student in the Faculty of Education, at The University of Hong Kong. She received her B.Sc. from University of Sydney. She is now investigating in-service teachers' classroom instruction on nature of science in relation to their intentions, beliefs, and pedagogical content knowledge.

Derek Hodson is Professor of Science Education at the Ontario Institute for Studies in Education and Editor of the Canadian Journal of Science, Technology and Mathematics Education. His major research interests include: history, philosophy \& sociology of science and its implications for science education; STSE education and the politicisation of science education; science curriculum history; multicultural and antiracist education; and science teacher education via action research.

Benny Hin Wai Yung is Head, Associate Professor, in the Division of Science, Mathematics and Computing in the Faculty of Education at University of Hong Kong. His main research areas are teacher education and development, science education and assessment for science learning. His recent publications include Yung BHW (2006) Assessment reform in science education: fairness and fear. Springer, Dordrecht. 